\title{
DADOS PRELIMINARES DA INSERÇÃO DO DISPOSITIVO INTRA UTERINO (DIU) NO PÓS PARTO E ABORTO EM UMA MATERNIDADE DE SÃO PAULO
}

\author{
Eixo temático: Avaliação e Qualidade do Cuidado
}

\author{
Jussara Leiko Terra; Lorrany Coelho Assunçãosato Tebet; Patricia Moreira Petrongari; Luciano Guerra; Rafael \\ Andrey
}

\section{INTRODUÇÃO}

A gravidez não planejada no Brasil é elevada cerca de $55 \%$ e em adolescentes temos uma média de $66 \%$. O DIU (Dispositivo Intrauterino) é um método contraceptivo seguro, reversível e eficaz, associado a poucos efeitos colaterais. Além disso, é o mais frequente no mundo, ao qual se relacionam taxas de falhas extremamente baixas, de menos de 1 gravidez por 100 mulheres no primeiro ano de uso. $O$ mecanismo de ação principal deve-se à produção de uma reação inflamatória, citotóxica, que é espermicida, que compromete a qualidade e a viabilidade dos espermatozóides. Os efeitos adversos mais comuns são o aumento do sangramento e da cólica menstrual (exceto naqueles com progestágenos).

\section{OBJETIVO}

Divulgar as evidências científicas sobre a inserção do DIU no pós parto e no pós aborto imediato e apresentar os resultados da inserção de DIU pós parto e aborto na maternidade municipal de São Paulo.

\section{RESULTADOS}

Segundo dados coletados no livro de parto da maternidade de Janeiro a Agosto de 2018 foram inseridos 26 DIUs pós aborto, 363 DIUs pós parto normal e 59 DIUs pós parto cesárea. Baseados em dados preliminares, a taxa de expulsão em 6 meses foi de $3,0 \%$ para parto normal e $5,3 \%$ em partos cesáreas e pós aborto menos de $1,0 \%$.

\section{DISCUSSÃO}

Características deste método contraceptivo: Efetivo, seguro, ação prolongada e reversível. Quem pode utilizar? Quase todas as mulheres no pós-parto (normal ou cesárea) e no pós aborto podem receber a inserção do DIU de cobre. A contraindicação está relacionada somente a quadros de risco infeccioso e de hemorragia. DIU no pós parto normal (taxas de expulsão)? Inserção imediata (até 10 minutos da dequitação): $9 \%$ de expulsão em 6 meses. DIU na cesárea? Inserção imediata na cesárea $=10,6 \%$ taxa de expulsão em 6 meses

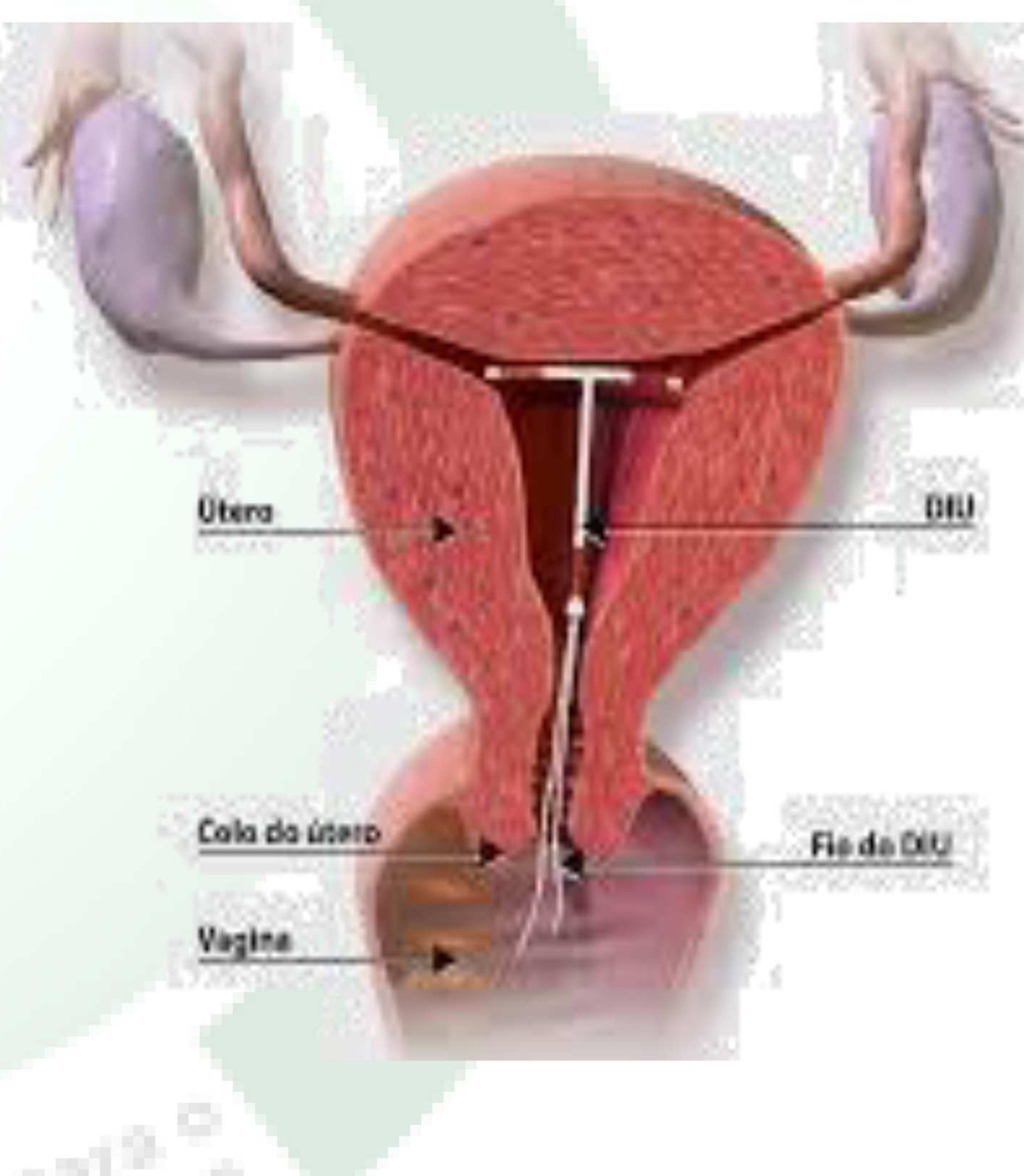

\section{CONCLUSÃO}

A inserção regular do DIU de cobre no pós-parto e no pós-aborto é uma excelente estratégia para reduzir a gravidez não planejada e melhorar os indicadores de mortalidade materna e infantil; Existem evidências científicas de que os gestores e profissionais devem implementar esta ação; Os serviços podem utilizar a lista de verificação para superar as barreiras de acesso a este método nas maternidades

\section{REFERÊNCIA}

ACOG. Practice Bulletin No. 186 Summary: Long-Acting Reversible Contraception: Implants and Intrauterine Devices. Obstetrics \& Gynecology 2017; 130(5): 1173-1175. 